\title{
IMPLEMENTASI METODE INCREMENTAL PADA SISTEM INFORMASI ADMINISTRASI DESA JAMBUWER
}

\author{
Evi Dwi Wahyuni ${ }^{1, *}$, Muhammad Risvi Khowiyu Azis ${ }^{2}$, Ilyas Nuryasin ${ }^{3}$ \\ 1,2,3 Teknik, Teknik Informatika, Universitas Muhammadiyah Malang, Malang, Indonesia \\ Email: ${ }^{1}$ evidwi@umm.ac.id, ${ }^{2}$ isviazis354@gmail.com. ${ }^{3}$ ilyas@umm.ac.id
}

\begin{abstract}
Abstrak - Desa Jambuwer adalah sebuah desa yang membutuhkan sistem informasi administrasi kependudukan yang dapat melakukan pengolahan data terkait proses pemberian layanan informasi tentang Desa Jambuwer seperti mencetak surat keteranganan, surat pernyataan, surat pengajuan dan pengolahan data RT dan RW. Dalam pelayanan dan informasi ke publik masih dilakukan secara manual, semua data dicatat ke dalam buku. Untuk pembuatan surat keterangan tidak mampu, surat keterangan penerimaan pensiun, surat pernyataan ahli waris harus mencari data terlebih dahulu di buku-buku penduduk induk. Sedangkan untuk mendapatkan informasi, masyarakat diharuskan untuk meluangkan waktu datang ke kantor. Hambatan yang dihadapi dalam proses mendapatkan informasi tersebut adalah aktivitas yang memakan waktu ketika masyarakat harus hadir ke kantor Desa dan risiko kesalahan petugas dalam pencatatan data. Hal ini bisa diatasi dengan membangun sistem baru yang lebih efektif yaitu sistem informasi administrasi Desa Jambuwer. Analisis pada sistem ini menggunakan analisis Elisitasi tahap 1, dan elisitasi tahap 2, dan MDI (Mandatory, Desirable, and Inessential). Untuk teknik pengembangan sistem menggunakan metode Incremental. Software yang digunakan untuk membangun sistem ini adalah Laravel dan XAMPP sebagai koneksi ke database MySQL. Setelah melakukan implementasi menggunakan metode incremental, peneliti melakukan tahapan pengujian menggunakan metode UAT untuk mengetahui penerimaan pengguna terhadap sistem informasi administrasi Desa Jambuwer. Dari hasil yang didapatkan pada pengujian UAT mendapatkan hasil yang baik dan dapat diterima oleh pengguna sistem.
\end{abstract}

Kata Kunci: Laravel, Sistem Informasi administrasi, Web, Xampp, PHP

Abstract - Jambuwer Village is a village that requires a population administration information system that can perform data processing related to the process of providing information services about Jambuwer Village, such as printing certificates, statement letter, submission letter and processing RT and RW data. In providing services and information to the public, it is still done manually, all data is recorded in books. To make a certificate of incapacity, a certificate of acceptance of pensions, a statement letter that the heirs must first look for data in the books of the main population. Meanwhile, to find out the information society should take the time to come to the office. The obstacles faced in the process of obtaining this information are time-consuming activities when the community must attend the village office and the risk of officer's errors in recording data. This can be overcome by building a new, more effective system, namely the Jambuwer village administrative information system. The analysis in this system uses stage 1 elicitation analysis, stage 2 elicitation, and MDI (Mandatory, Desirable, and Inessential). For system development technique using the Incremental method. The software used to build this system is Laravel and XAMPP as a connection to the MySQL database. After implementing the incremental method, the researcher carried out the testing phase using the UAT method to determine user acceptance of the Jambuwer Village administrative information system. From the results obtained in the UAT test got good results and can be accepted by system users.

Keywords: Laravel, administrative information systems, Web, Xampp 


\subsection{Latar Belakang}

\section{PENDAHULUAN}

Saat ini, dunia telah mengenal teknologi yaitu internet. Dengan adanya internet semua orang bisa berkomunikasi jarak jauh dengan orang lain baik teman maupun kerabatnya. Melalui media ini juga semua orang dapat mengirimkan berbagai informasi yang dibutuhkan dimanapun dan kapanpun. Saat ini internet tidak hanya digunakan untuk mencari informasi saja, tetapi juga digunakan untuk berbisnis dengan cara membangun sebuah website. Sistem informasi merupakan salah satu bentuk pemanfaatan teknologi internet yang dapat membantu pekerjaan dan mengurangi waktu kerja seseorang [1]. Salah satu system informasi yang dapat membantu pekerjaan dan menghemat waktu adalah system informasi administrasi pada sebuah instansi. Dengan adanya system informasi administrasi diharapkan dapat membantu instansi dalam menyelesaikan beberapa tugas yang berhubungan dengan layanan terhadap penggunanya.

Desa Jambuwer berada dalam wilayah kecamatan Kromengan kab. Malang (perbatasan Blitar). Desa ini terletak pada ketinggian 433 meter diatas permukaan air laut dan memiliki luas tanah sebesar 656,577 hektar. Menurut data desa dalam website data warga milik Kabupaten Malang memiliki jumlah penduduk sebanyak 5.815 jiwa yang terbagi laki-laki berjumlah 2.869 dan perempuan berjumlah 2.956 jiwa. Pemanfaatan lahan di Desa Jambuwer : Pemukiman seluas 88,27 hektar, Pertanian Sawah seluas 142,11 hektar, Ladang/Tegalan seluas 185,38 hektar, Perkebunan seluas 172,28 hektar, Hutan Rakyat seluas 3,10 hektar, Bangunan seluas 23,23 hektar, lapangan olahraga seluas 0,09 hektar, perikanan air tawar seluas 3.15, lain-lain seluas 24,29 hektar. Hal ini berarti Desa Jambuwer memiliki wilayah yang sangat luas.

Berdasarkan hasil wawancara kepada kepala desa dan pengurus desa pada tanggal 28 Desember 2019, diperoleh informasi bahwa permasalahan yang ada di desa Jambuwer Kecamatan Kromengan Kabupaten Malang adalah pengolahan data kependudukan yang sedang berjalan saat ini masih dicatat ke dalam buku data kependudukan. Dalam memberikan pelayanan dan informasi kepada masyarakat masih dilakukan secara manual dan membutuhkan penyimpanan data yang besar, semua data dicatat ke dalam buku data kependudukan. Untuk pembuatan kartu tanda penduduk, kartu keluarga dan mutasi penduduk harus mencari data terlebih dahulu di dalam buku induk kependudukan Sedangkan untuk mendapatkan informasi, masyarakat diharuskan untuk meluangkan waktu datang ke kantor. Dengan bisnis proses yang masih dilakukan secara manual tersebut tentu saja membutuhkan waktu yang cukup lama, sehingga akan menghambat pelayanan kepada masyarakat [2].

Metode yang digunakan untuk pembangunan Sistem Informasi Administrasi Desa sendiri menggunakan metode Incremental yang merupakan pengembangan dari metode waterfall yang sering digunakan untuk pengembangan perangkat lunak. Pembeda dan keunggulan dari metode Incremental ini adalah tahapan proses dapat dilakukan secara paralel, sehingga bila satu tahapan belum selesai bisa mengerjakan tahapan lain [3]. Model ini dapat digunakan pada saat sumber daya tim pengembang terbatas. Hal ini dikarenakan model incremental dibagi menjadi beberapa bagian yang lebih kecil (software release). Selain itu, terdapat feedback pada setiap software release membuat kebutuhan pengguna semakin jelas. Model Incremental juga dapat meminimalisir resiko cacat/bug selama proses pengembangan perangkat lunak karena setiap release dilakukan pengujian secara bertahap.

\section{METODE PENELITIAN}

\subsection{Tahapan Penelitian}

Pada incremental Model, spesifikasi kebutuhan yang sudah diperoleh akan ditempatkan pada setiap increment atau disebut dengan fase independent dalam pembagian sistem modul [4]. Produk yang dihasilkan pada increment pertama (core product) bukanlah prototype, tapi produk yang sudah bisa berfungsi dengan spesifikasi dasar [5]. Fase-fase yang terdapat pada incremental model dapat dilihat pada gambar berikut: 

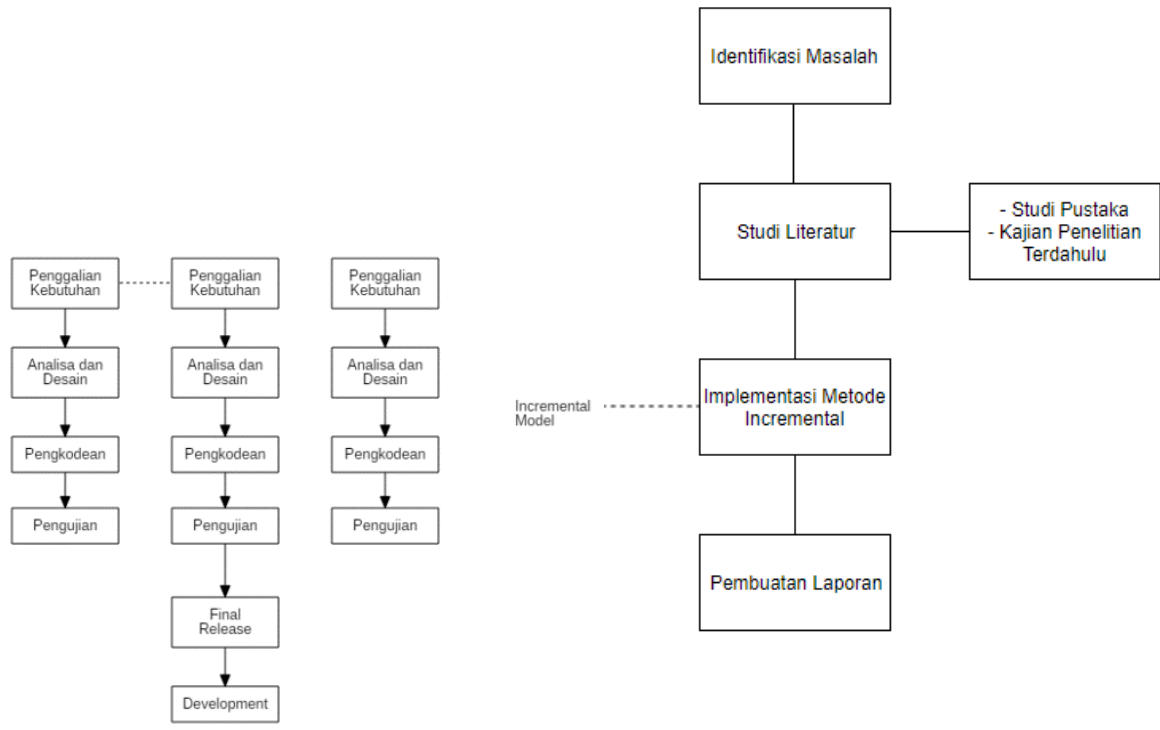

Gambar 1. Tahapan Implementasi Incremental

\subsubsection{Identifikasi Masalah}

Pada tahapan identifikasi masalah dilakukan penggalian informasi tentang masalah yang terjadi pada pelayanan administrasi Desa Jambuwer. Identifikasi masalah dilakukan dengan metode wawancara dan observasi. Pada tahapan wawancara peneliti melakukan wawancara kepada Pak Rudi Widodo yang juga merangkap sebagai admin dan juga Perangkat Desa Jambuwer untuk mempertanyakan permasalahan apa yang terjadi pada pelayanan administrasi Desa Jambuwer. Pada tahapan observasi peneliti datang langsung untuk memperhatikan permasalahan yang terjadi pada pelayanan administrasi Desa Jambuwer dan juga untuk memperkirakan solusi yang tepat dari permasalahan pada pelayanan administrasi Desa Jambuwer.

\subsubsection{Studi Pustaka}

Dalam melakukan penelitian ilmiah harus dilakukan teknik penyusunan yang sistematis untuk memudahkan langkah-langkah yang akan diambil. Begitu pula yang dilakukan penulis dalam penelitian ini, langkah pertama yaitu dengan melakukan studi literatur pada buku-buku yang membahas tentang Theory of Constraints, jurnal, dan penelitian yang telah dilakukan yang berkaitan dengan topik penelitian [6].

2.1.3 Kajian Penelitian Terdahulu

Kajian penelitian dilakukan untuk mengetahui beberapa penelitian yang serupa dengan penelitian yang dilakukan.

\subsubsection{Implementasi Metode Incremental}

Pada tahap ini akan menjelaskan tahapan - tahapan implementasi pengembangan website menggunakan metode incremental yang dimulai dari Analisis Kebutuhan, Desain, Pengkodean, serta Pengujian [7]. 


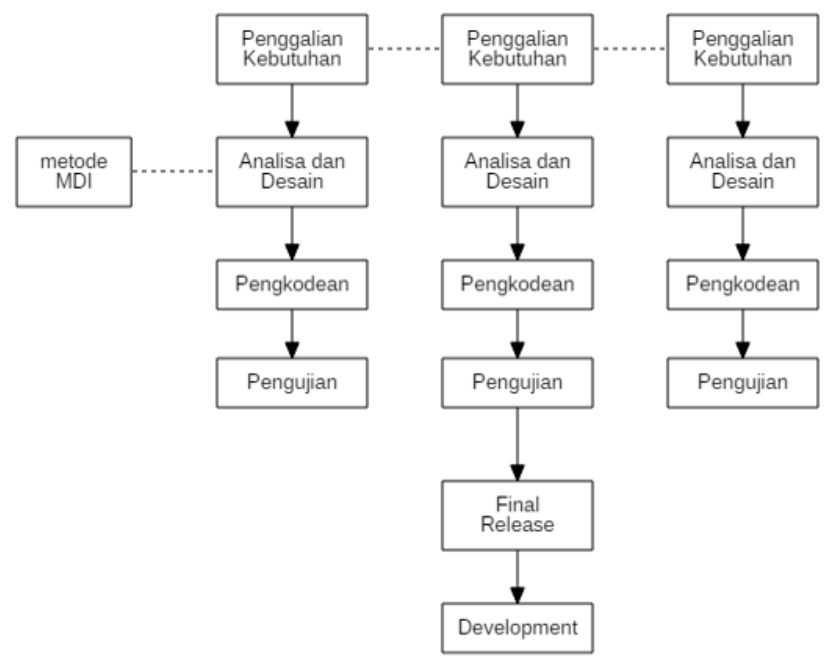

Gambar 2. Alur Metode Incremental

\subsubsection{Penggalian Kebutuhan}

Tahap Analisa Kebutuhan adalah tahap penggalian kebutuhan, dimana pada tahap ini dilakukan pengumpulan kebutuhan apa saja yang dibutuhkan pada proses pengembangan sistem. Langkah selanjutnya yaitu membagi kebutuhan fungsional dan non-fungsional untuk memudahkan mana kebutuhan yang harus dirancang pada sistem dan mana kebutuhan pendukung untuk jalannya website tersebut. Adapun kebutuhan fungsional dan nonfungsional yaitu sebagai berikut:

Tabel 1. Elisitasi Tahap 1

\begin{tabular}{|l|l|}
\hline \multicolumn{2}{|c|}{ Functional } \\
\hline No & \multicolumn{1}{|c|}{ Analisa Kebutuhan } \\
\hline 1 & Sistem dapat melakukan login \\
\hline 2 & Sistem dapat view data warga \\
\hline 3 & Sistem dapat tambah user \\
\hline 4 & Sistem dapat view data user \\
\hline 5 & Sistem dapat view data surat \\
\hline 6 & Sistem dapat mencetak surat \\
\hline 7 & Sistem dapat kelola data warga \\
\hline 8 & Sistem dapat kelola data surat permohonan kematihan \\
\hline 9 & Sistem dapat kelola data surat permohonan pindah \\
\hline 10 & Sistem dapat kelola data surat permohonan KK \\
\hline 11 & Sistem dapat kelola data surat permohonan KTP \\
\hline 12 & Sistem dapat kelola data surat keterangan kelahiran \\
\hline 13 & Sistem dapat kelola data surat pengantar ijin keramaian \\
\hline 14 & Sistem dapat kelola data surat catatan kepolisian \\
\hline 15 & Sistem dapat kelola data surat pengantar umum \\
\hline 16 & Sistem dapat kelola data surat pernyataan umum \\
\hline 17 & Sistem dapat kelola data surat pemberitahuan umum \\
\hline 18 & Sistem dapat kelola data surat keterangan domisili usaha \\
\hline 19 & Sistem dapat kelola data surat keterangan domisili tempat tinggal \\
\hline 20 & Sistem dapat kelola data surat keterangan usaha \\
\hline 21 & Sistem dapat kelola data surat keterangan tidak mampu \\
\hline 22 & Sistem dapat kelola data surat keterangan umum \\
\hline 23 & Sistem dapat melakukan logout \\
\hline 24 & Sistem dapat melakukan pencarian otomatis \\
\hline 25 & Menampilkan home \\
\hline & Non Functional \\
\hline & \\
\hline
\end{tabular}




\begin{tabular}{|l|l|}
\hline No & \multicolumn{1}{|c|}{ Analisa Kebutuhan } \\
\hline 1 & Menggunakan Mysql sebagai database \\
\hline 2 & Menampilkan username dan password pada saat login \\
\hline 3 & Tampilan sistem mudah digunakan dan dipahami oleh user \\
\hline 4 & Keamanan data terjamin \\
\hline
\end{tabular}

\subsubsection{Analisa}

Pada fase ini akan dilakukan analisa dari data primer yang sudah diperoleh pada tahapan seelumnya yang akan menghasilkan spesifikasi kebutuhan perangkat lunak. Kemudian, spesifikasi kebutuhan yang diperoleh tersebut akan dimodelkan kedalam desain seperti UML (Unifed Modeling Language), atau class diagram[8]. Berdasarkan hasil Analisa kebutuhan yang dilakukan, dapat digambarkan dalam use case berikut ini:

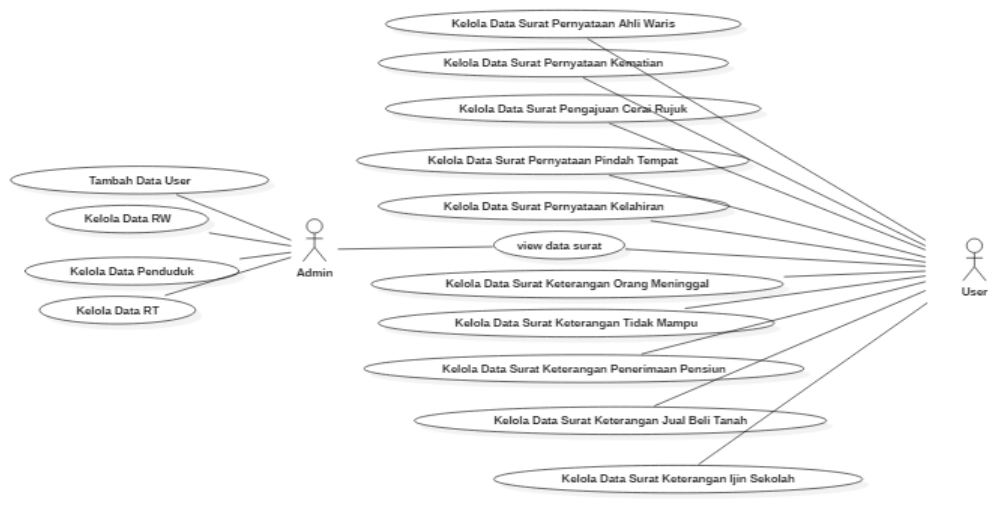

Gambar 3. Use Case diagram

Pada use case diagram tersebut terdapat 2 aktor yaitu admin dan user, user disini adalah petugas aparatur desa yang memiliki tugas dalam memberikan layanan kepada masyarakat. Sedangkan admin sebagai admin utama yang dapat menambahkan data petugas siapa saja yang dapat menggunakan sistem dan beberapa kemampuan lain yang berhubungan dengan penambahan data master system.

\subsubsection{Desain}

Pada tahap ini dilakukan pembuatan desain yang memberikan gambaran kepada pengguna dimana desain sistem yang akan dibuat berdasarkan dari hasil wawancara yang telah dilakukan sebelumnya. Kebutuhan sistem yang didapat dari hasil wawancara selanjutnya di implementasikan kedalam bentuk desain interface yang akan di serahkan kepada pengguna untuk dicek apakah kebutuhan sistem sesuai dengan hasil wawancara.

\subsection{Desain Arsitektur}

Dibawah ini adalah arsitektur atau desain untuk tampilan admin dan pengguna dari sistem yang akan dibuat.

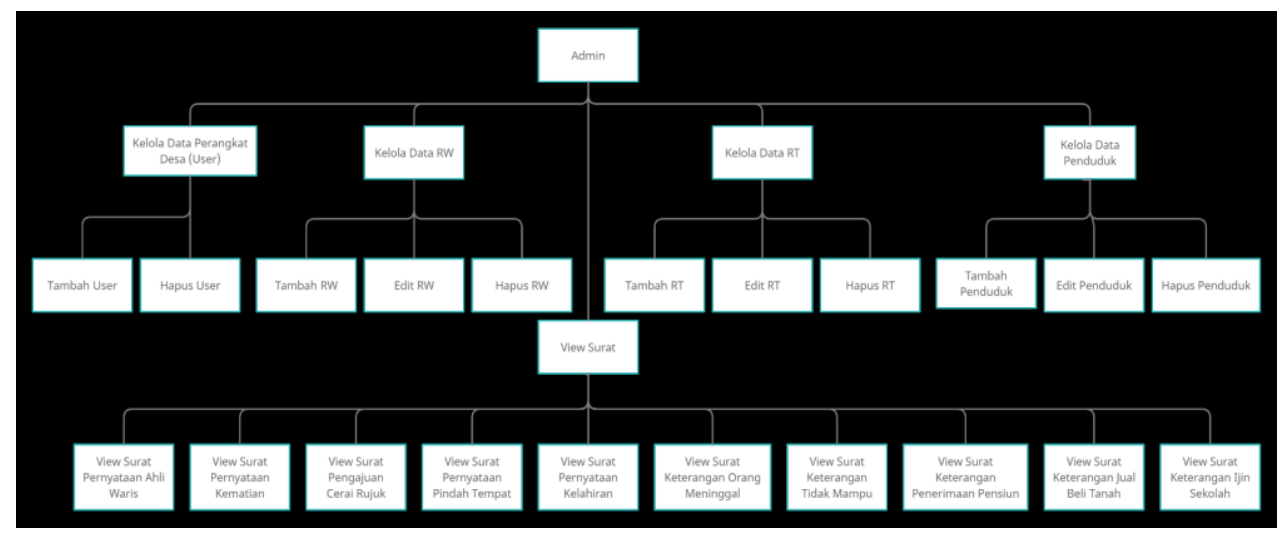

Gambar 4. Desain Arsitektur Sistem Admin 

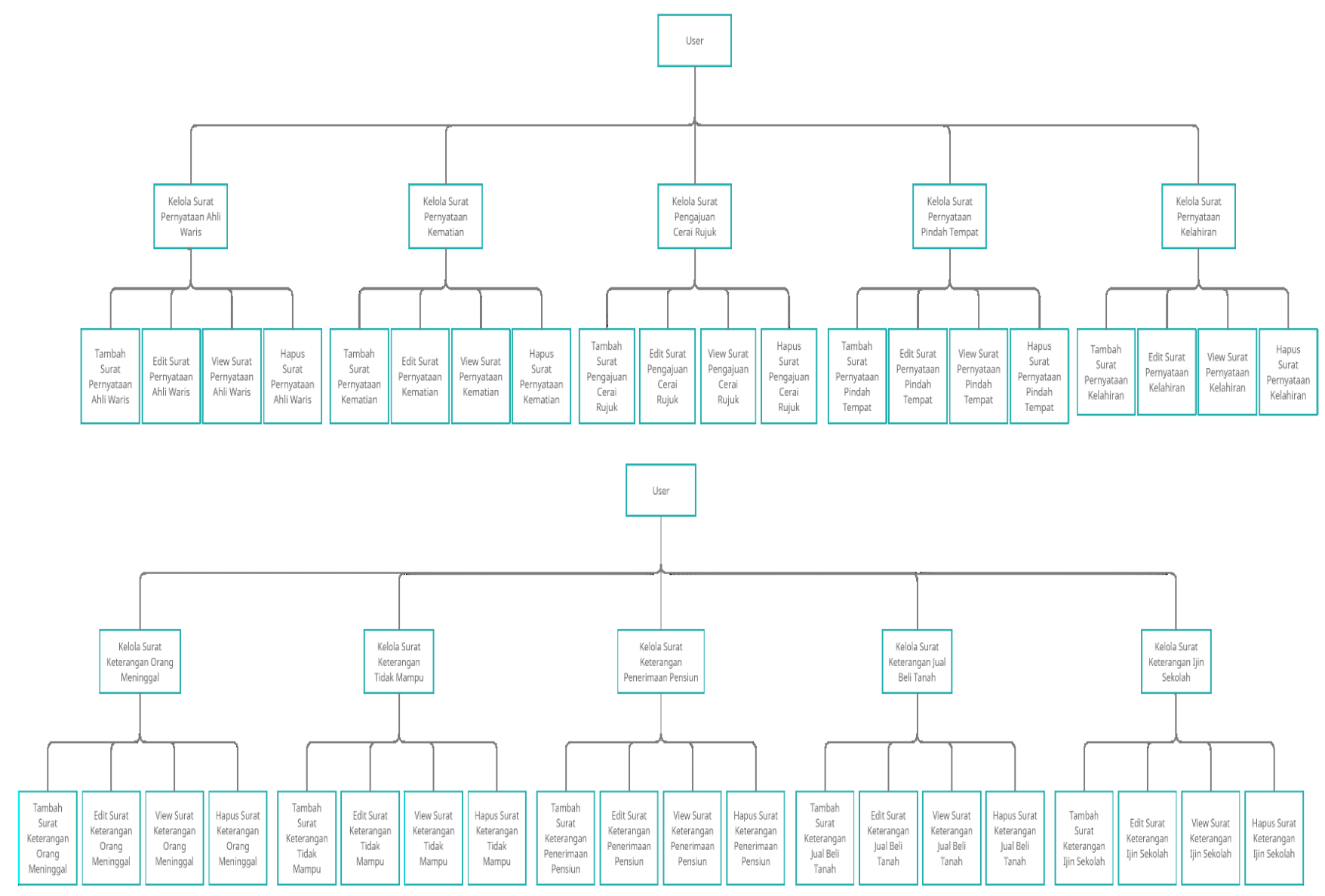

\subsubsection{Pengkodean}

Gambar 5. Desain Arsitektur Sistem Pengguna

Hasil desain dari tahapan sebelumnya direalisasikan dengan melakukan coding. Proses coding merupakan tahap implementasi desain dengan bahasa pemrograman sehingga dapat dikenali oleh komputer. Pada tahap pengkodean peneliti menggunakan framework laravel yang didalamnya terdapat Bahasa pemrograman HTML, CSS, dan PHP serta menggunakan Boostrap sebagai tampilan awal. Manajemen database yang digunakan adalah My SQL yang bersifat open source. Sistem database MySQL mendukung fitur seperti multithreaded, multiuser dan SQL Database Manajemen Sistem (DBMS). Database ini dibuat untuk keperluaan sistem database yang cepat, handal dan mudah digunakan [9]. Tahap ini merupakan tahap nyata dari pembangunan perangkat lunak [10].

\subsubsection{Pengujian}

Developer atau pengembang melakukan pengujian terhadap setiap increment atau system module setelah tahap pengkodean selesai. Pengujian berfungsi untuk mengetahui apakah sistem informasi yang dibangun sudah sesuai harapan atau belum. Jika sudah memenuhi maka akan lanjut ke increment selanjutnya. Pada tahap ini dilakukan pengujian UAT (User Acceptance Test) untuk mengetahui fungsionalitas dari sistem yang dibangun. Tujuannya adalah mengetahui apakah sistem informasi yang dibangun sudah memenuhi kebutuhan dari calon pengguna seperti yang diidentifikasikan pada tahap analisa.

\subsubsection{Final Release}

Final release merupakan tahap akhir aplikasi yang sudah teruji dengan semua fitur yang sesuai dengan kebutuhan pengguna dan sudah tidak ada lagi perubahan lagi dan sudah siap diserahkan pada pengguna sesuai tanggal yang sudah disepakati oleh kedua pihak pengembang sistem maupun pengguna system.

\subsubsection{Development}

Yang terakhir yaitu tahap development. Dimana, sistem atau aplikasi sudah bisa di terapkan atau di pakai oleh pengguna. 


\subsubsection{Pembuatan Laporan}

Membuat laporan terkait hasil penelitian pembangunan Sistem Informasi Administrasi Desa Jambuwer berdasarkan semua tahap yang telah dilaksanakan.

\section{HASIL DAN PEMBAHASAN}

Pada bab ini akan menjelaskan hasil dan pembahasan dari penelitian yang telah dilakukan, yaitu pembahasan mengenai hasil implementasi sistem dan pengujian yang dilakukan yaitu dengan menggunakan metode UAT (User Acceptance Testing) untuk mengetahui bagaimana penerimaan pengguna.

\subsection{Implementasi Website Sistem Informasi Administrasi Desa Jambuwer}

Implementasi sistem merupakan perancangan dan pengembangan sistem berdasarkan hasil evaluasi yang telah dilakukan.sistem dikembangkan menggunakan Bahasa pemrograman yang dipilih.

\subsubsection{Tampilan Beranda Website}

Halaman beranda website merupakan tampilan awal saat pengguna menggunakan website. Pada beranda website terdapat menu login. Tampilan beranda website dapat dilihat pada gambar 6.

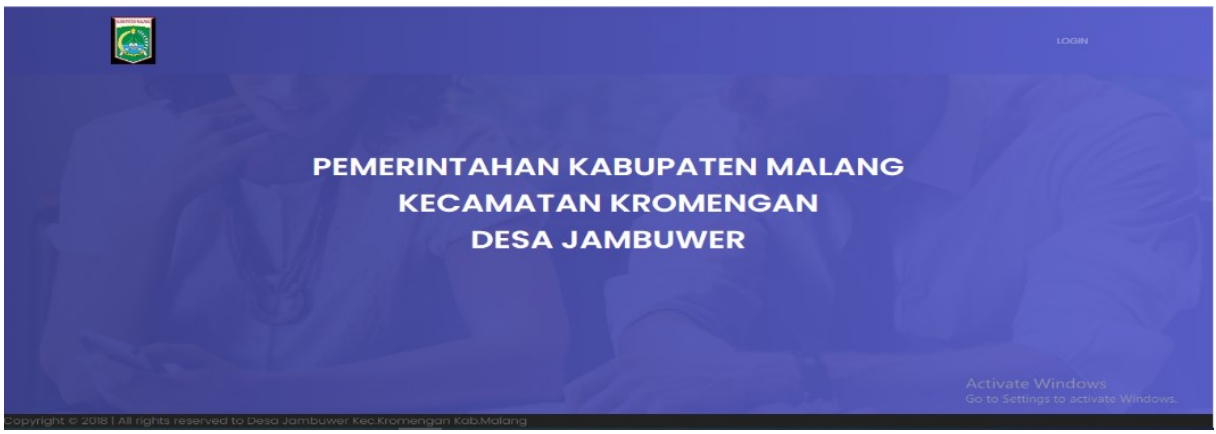

Gambar 6. Tampilan Beranda Website

\subsubsection{Tampilan Halaman Login Admin}

Pada halaman login terdapat kolom email dan password yang digunakan admin untuk masuk ke halaman dashboard. Terdapat juga checkbox "Ingatkan Saya" agar pengguna tidak perlu lagi mengetikkan email dan password saat akan login kembali. Tampilan login dapat dilihat pada gambar 7 .

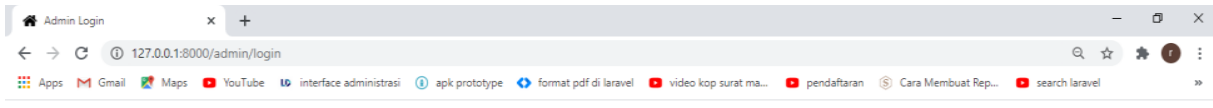

LOGIN

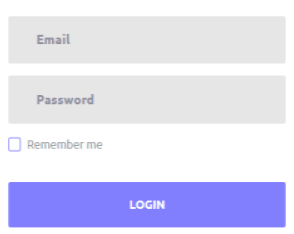

Gambar 7. Tampilan Halaman Login Admin

\subsubsection{Tampilan Halaman Dashboard Admin}

Pada halaman Dashboard Admin menampilkan beberapa menu yang digunakan admin untuk mengelola sistem informasi administrasi Desa Jambuwer. Tampilan dashboard admin dapat dilihat pada gambar 8. 


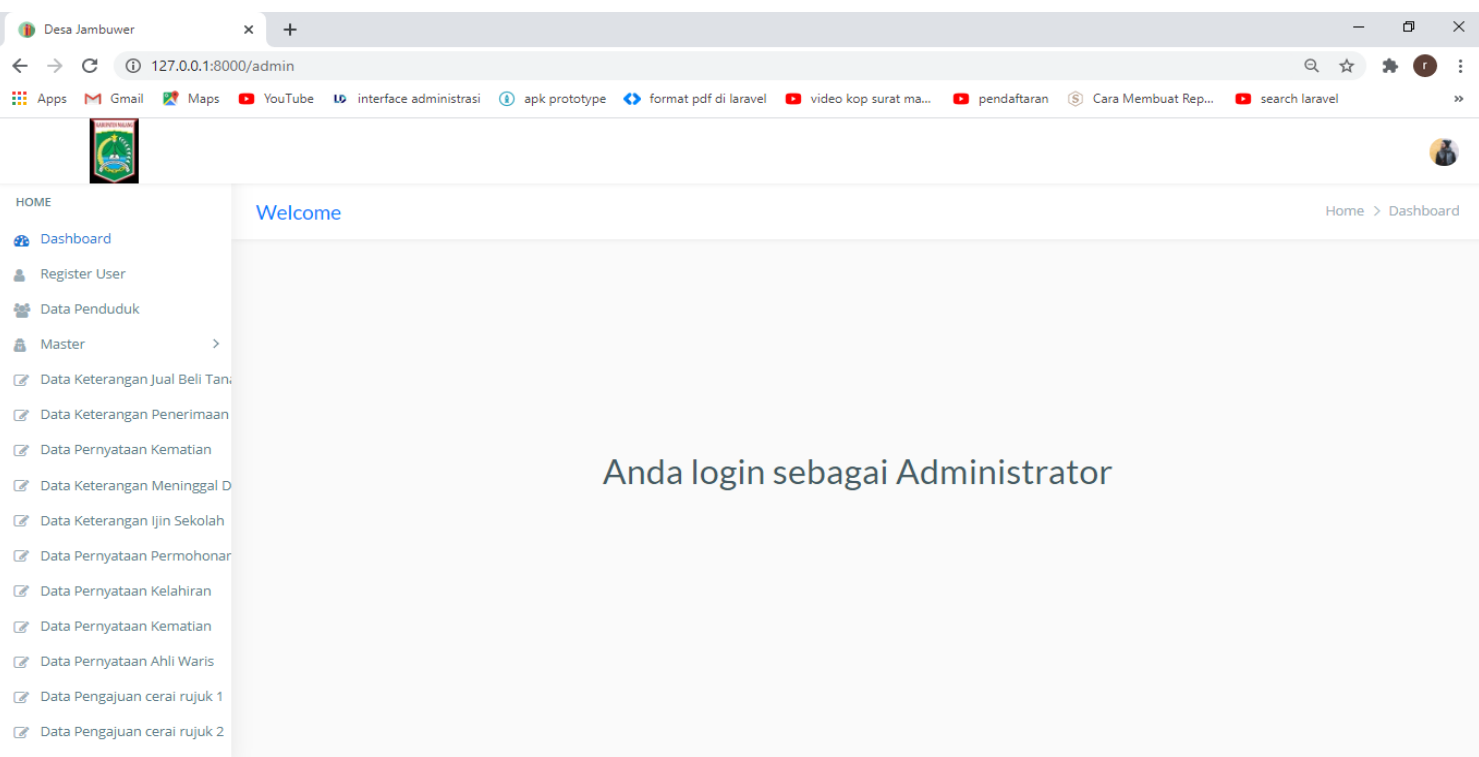

Gambar 8. Tampilan Halaman Login Admin

\subsubsection{Tampilan Halaman Login User}

Pada halaman login terdapat kolom email dan password yang digunakan user atau perangkat desa untuk masuk ke halaman dashboard. Terdapat juga checkbox "Ingatkan Saya" agar pengguna tidak perlu lagi mengetikkan email dan password saat akan login kembali. Tampilan login dapat dilihat pada gambar 9 .

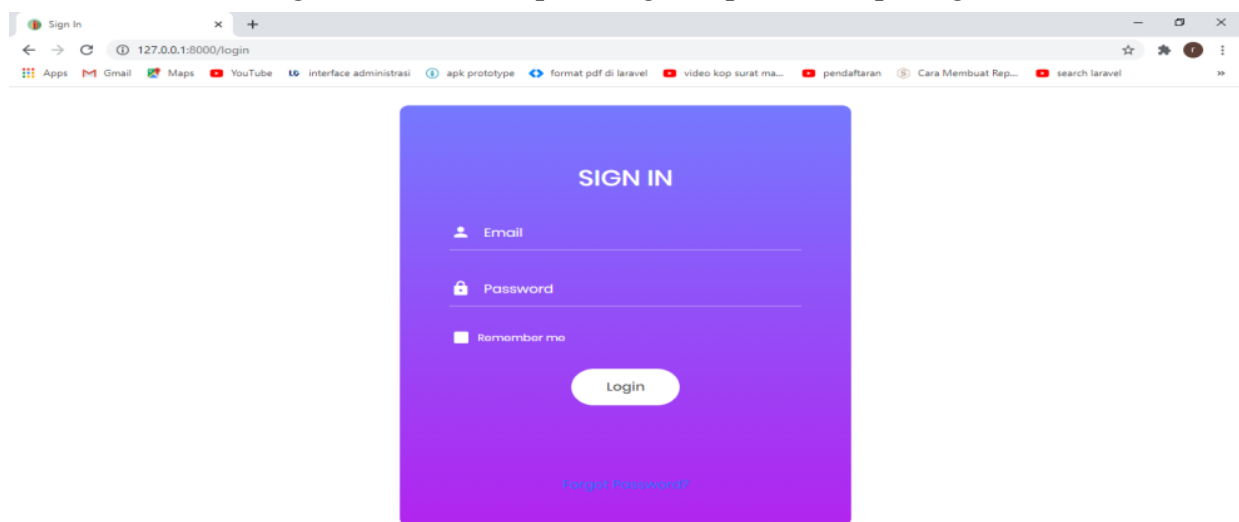

Gambar 9. Tampilan Halaman Login User

\subsubsection{Tampilan Halaman Dashboard User}

Pada halaman Dashboard User menampilkan beberapa menu yang digunakan pengguna dalam hal ini adalah petugas administrasi desa untuk mengelola sistem informasi administrasi desa jambuwer. Tampilan dashboard user dapat dilihat pada gambar 10 .

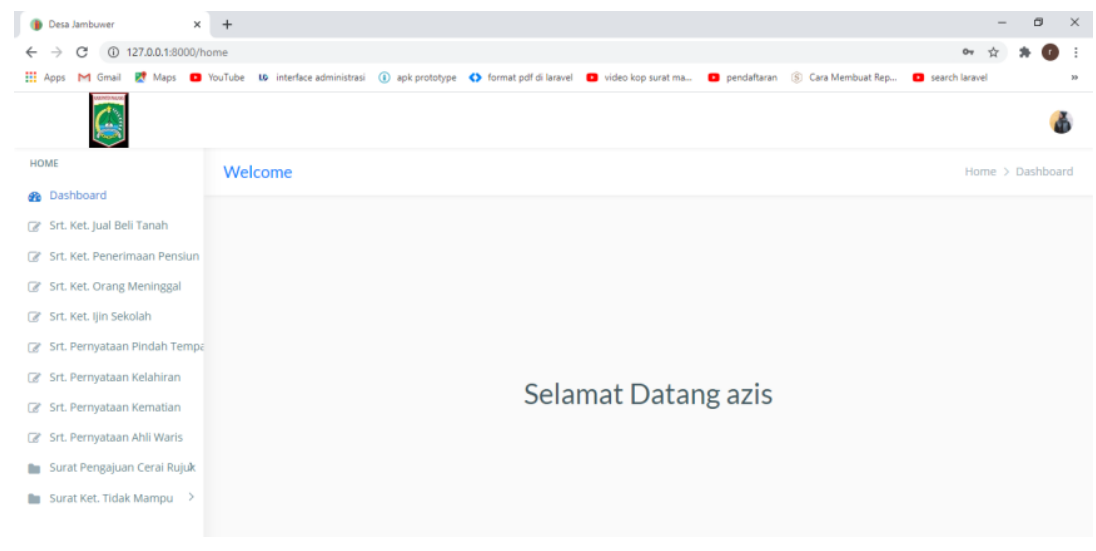

Gambar 10. Tampilan Halaman Dashboard User 


\subsubsection{Tampilan Halaman Kelola Surat Keterangan Jual Beli Tanah}

Pada halaman Kelola Data Surat Keterangan Jual Beli Tanah menampilkan daftar semua informasi data surat keterangan jual beli tanah yang telah di isi oleh user dengan data yang lengkap. Jika user ingin melihat detail dari data surat keterangan jual beli tanah maka user dapat mengklik tombol yang ada pada kolom aksi. Tampilan halaman view data surat keterangan jual beli tanah dapat dilihat pada gambar 11 .

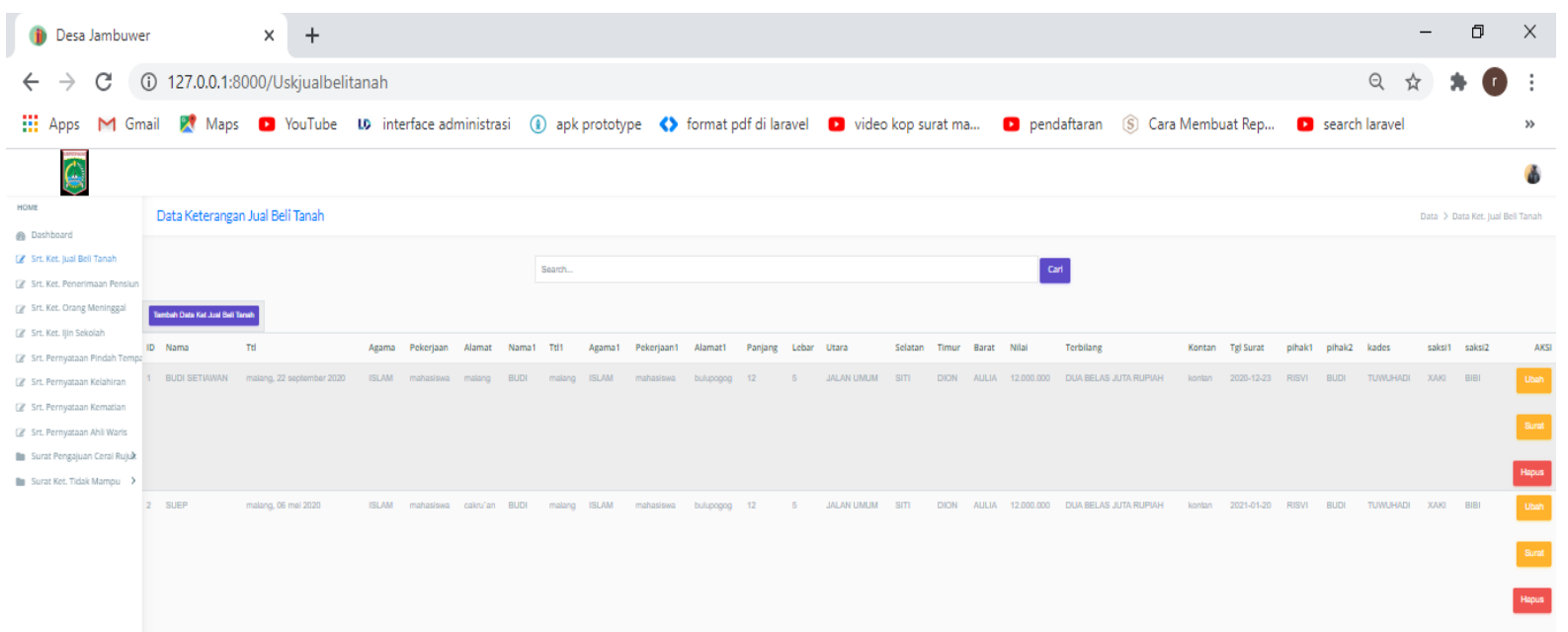

Gambar 11. Tampilan Halaman Kelola Surat Keterangan Jual Beli Tanah

\subsubsection{Tampilan Halaman Kelola Surat Keterangan Penerimaan Pensiun}

Pada halaman Kelola Data Surat Keterangan Penerimaan Pensiun menampilkan daftar semua informasi data surat keterangan penerimaan pensiun yang telah di isi oleh user dengan data yang lengkap. Jika user ingin melihat detail dari data surat keterangan penerimaan pensiun maka user dapat mengklik tombol yang ada pada kolom aksi. Tampilan halaman view data surat keterangan penerimaan pensiun dapat dilihat pada gambar 12 .

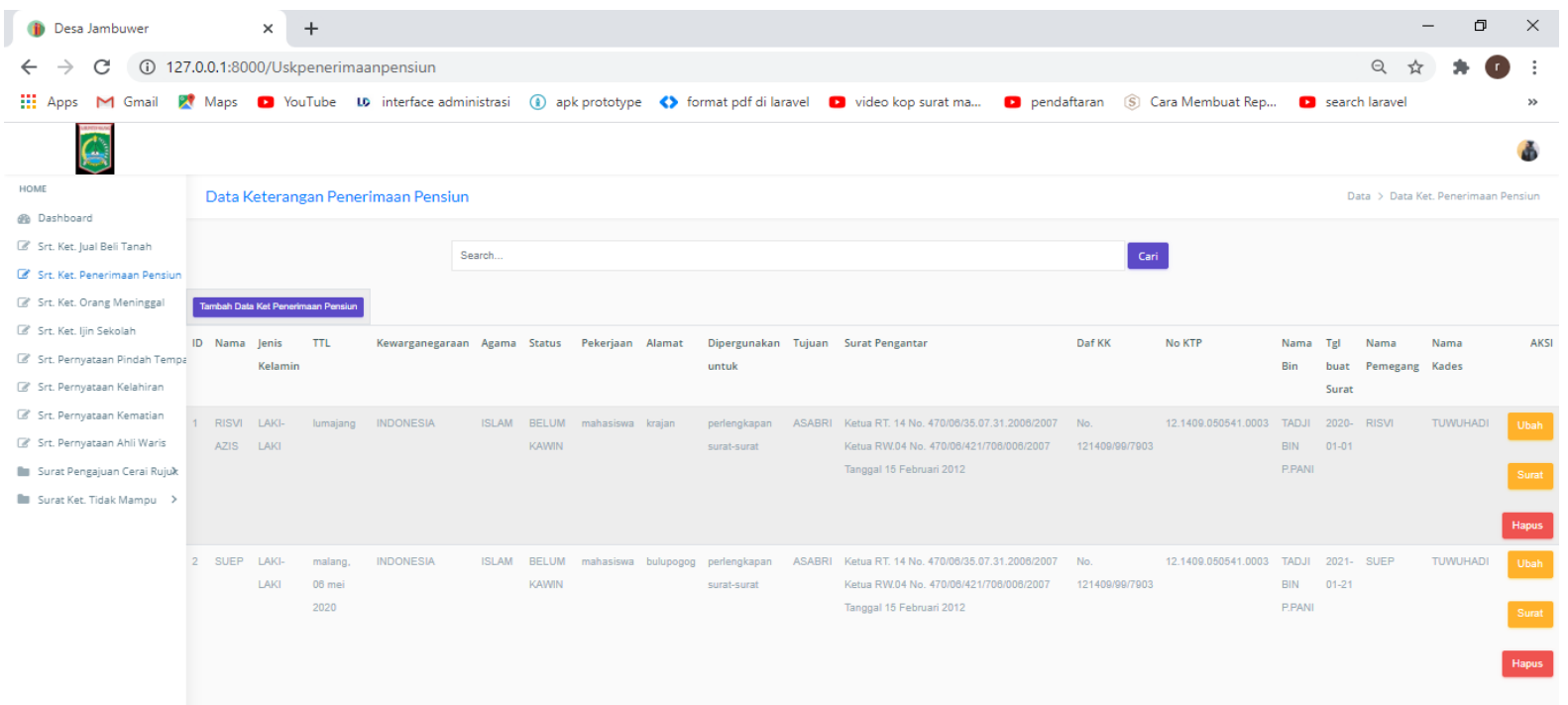

Gambar 12. Tampilan Halaman Kelola Surat Keterangan Jual Beli Tanah

\subsubsection{Tampilan Halaman Kelola Surat Keterangan Meninggal Dunia}

Pada halaman Kelola Data Surat Keterangan Meninggal Dunia menampilkan daftar semua informasi data surat keterangan meninggal dunia yang telah di isi oleh user dengan data yang lengkap. Jika user ingin melihat detail dari data surat keterangan meninggal dunia maka user dapat mengklik tombol yang ada pada kolom aksi. Tampilan halaman view data surat keterangan meninggal dunia dapat dilihat pada gambar 13. 


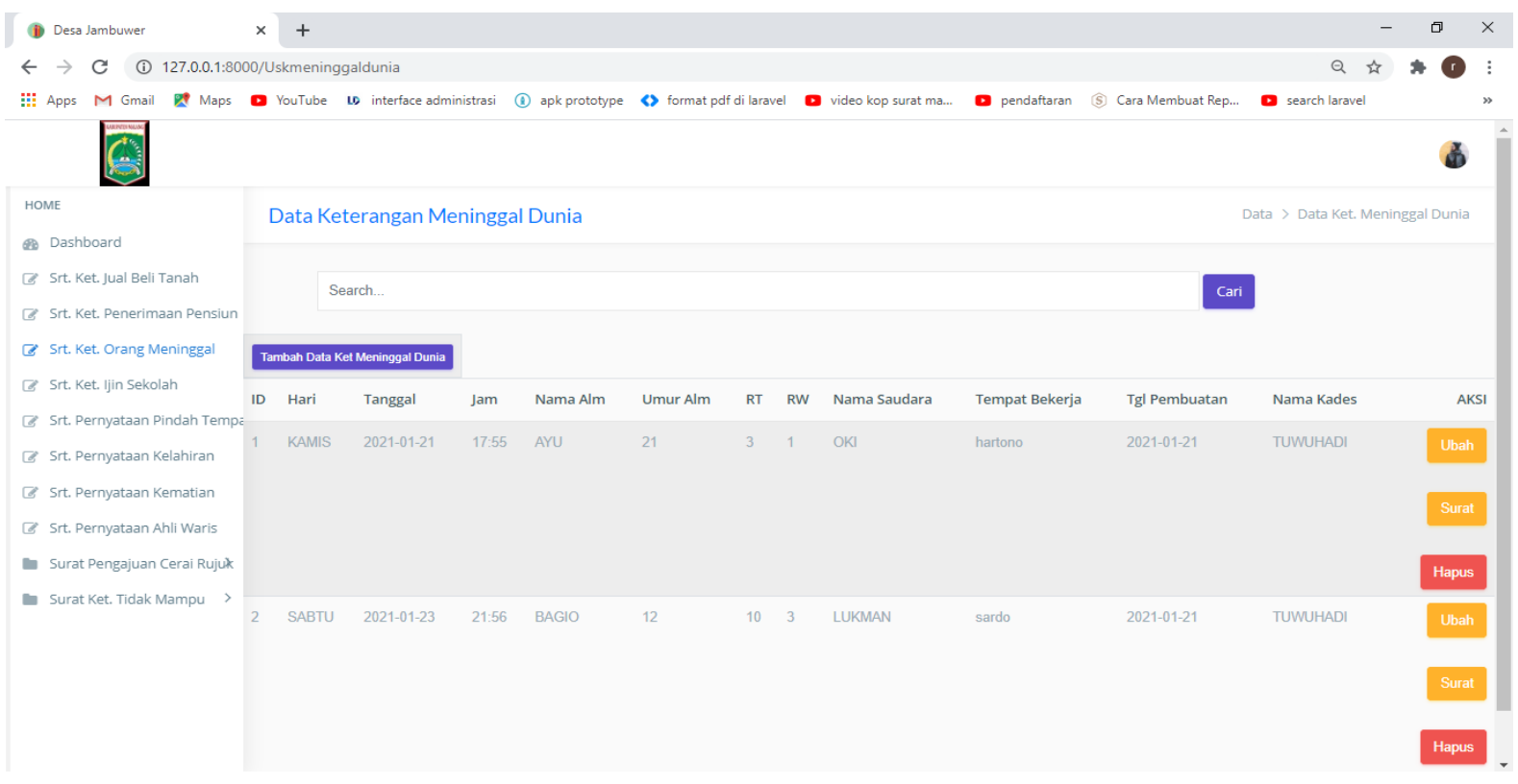

Gambar 13. Tampilan Halaman Kelola Surat Keterangan Meninggal Dunia

\subsubsection{Tampilan Halaman Kelola Surat Keterangan Ijin Sekolah}

Pada halaman Kelola Data Surat Keterangan Ijin Sekolah menampilkan daftar semua informasi data surat keterangan ijin sekolah yang telah di isi oleh user dengan data yang lengkap. Jika user ingin melihat detail dari data surat keterangan ijin sekolah maka user dapat mengklik tombol yang ada pada kolom aksi. Tampilan halaman view data surat keterangan ijin sekolah dapat dilihat pada gambar 14.

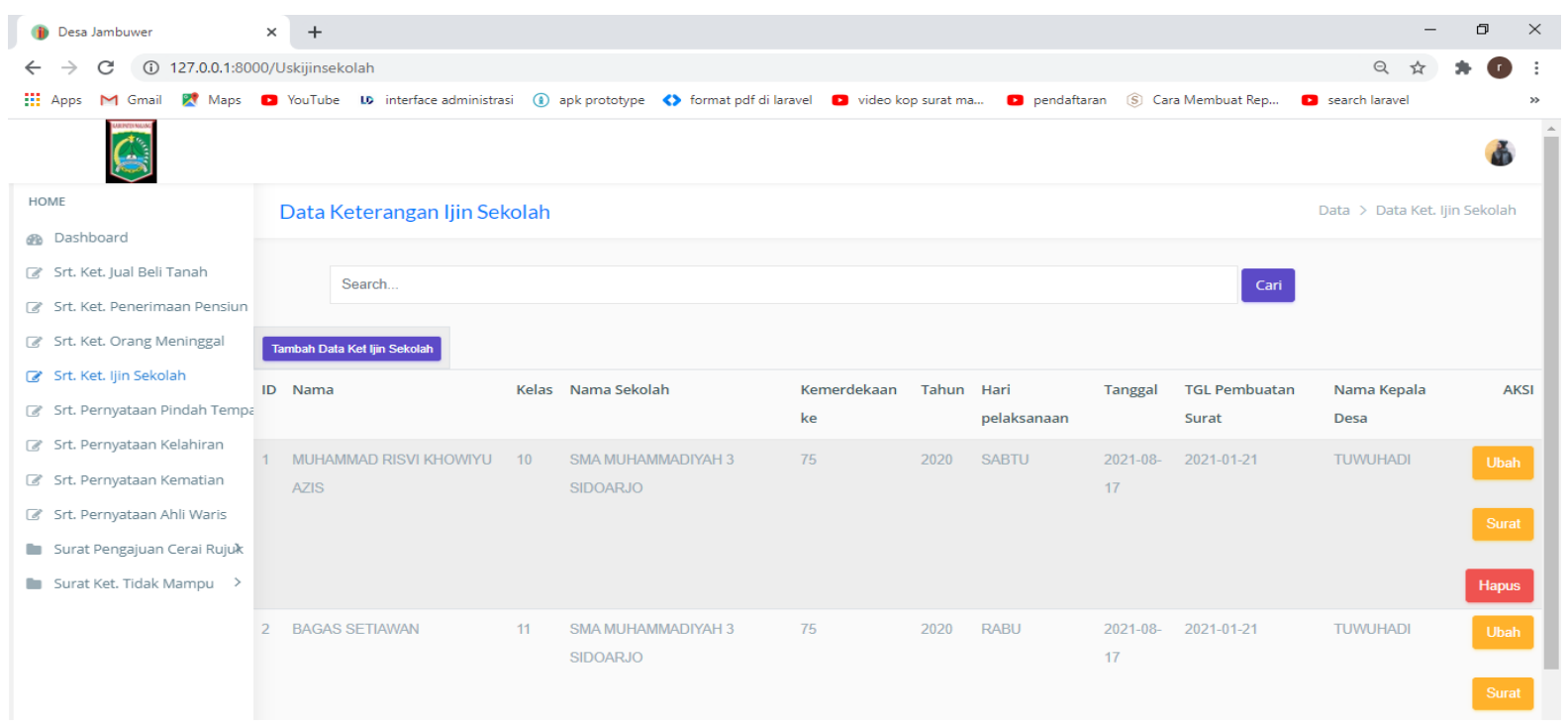

Gambar 14. Tampilan Halaman Kelola Surat Keterangan Ijin Sekolah

\subsubsection{Tampilan Halaman Kelola Surat Pernyataan Pindah Tempat}

Pada halaman Kelola Data Surat Pernyataan Pindah Tempat menampilkan daftar semua informasi data surat pernyataan pindah tempat yang telah di isi oleh user dengan data yang lengkap. Jika user ingin melihat detail dari data surat pernyataan pindah tempat maka user dapat mengklik tombol yang ada pada kolom aksi. Tampilan halaman view data surat pernyataan pindah tempat dapat dilihat pada gambar 15. 


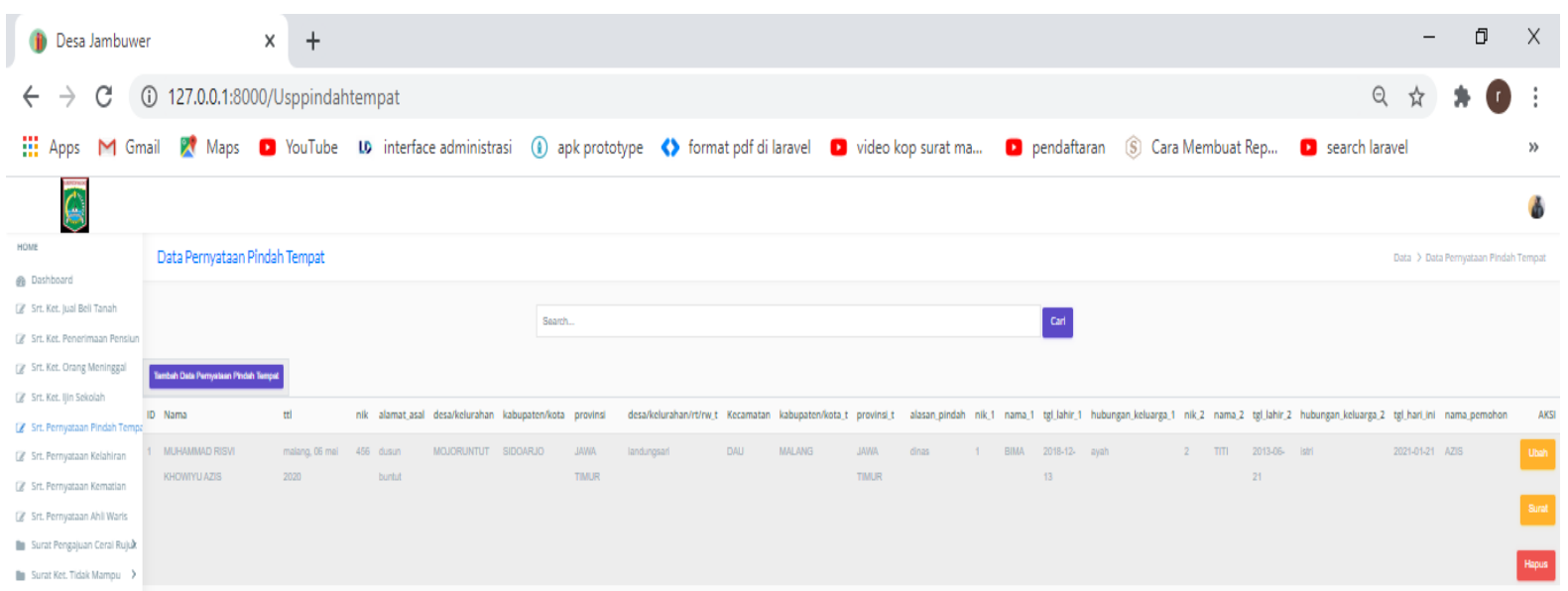

Gambar 15. Tampilan Halaman Kelola Surat Pernyataan Pindah Tempat

\subsubsection{Tampilan Halaman Kelola Surat Pernyataan Kelahiran}

Pada halaman Kelola Data Surat Pernyataan Kelahiran menampilkan daftar semua informasi data surat pernyataan kelahiran yang telah di isi oleh user dengan data yang lengkap. Jika user ingin melihat detail dari data surat pernyataan kelahiran maka user dapat mengklik tombol yang ada pada kolom aksi. Tampilan halaman view data surat pernyataan kelahiran dapat dilihat pada gambar 16.

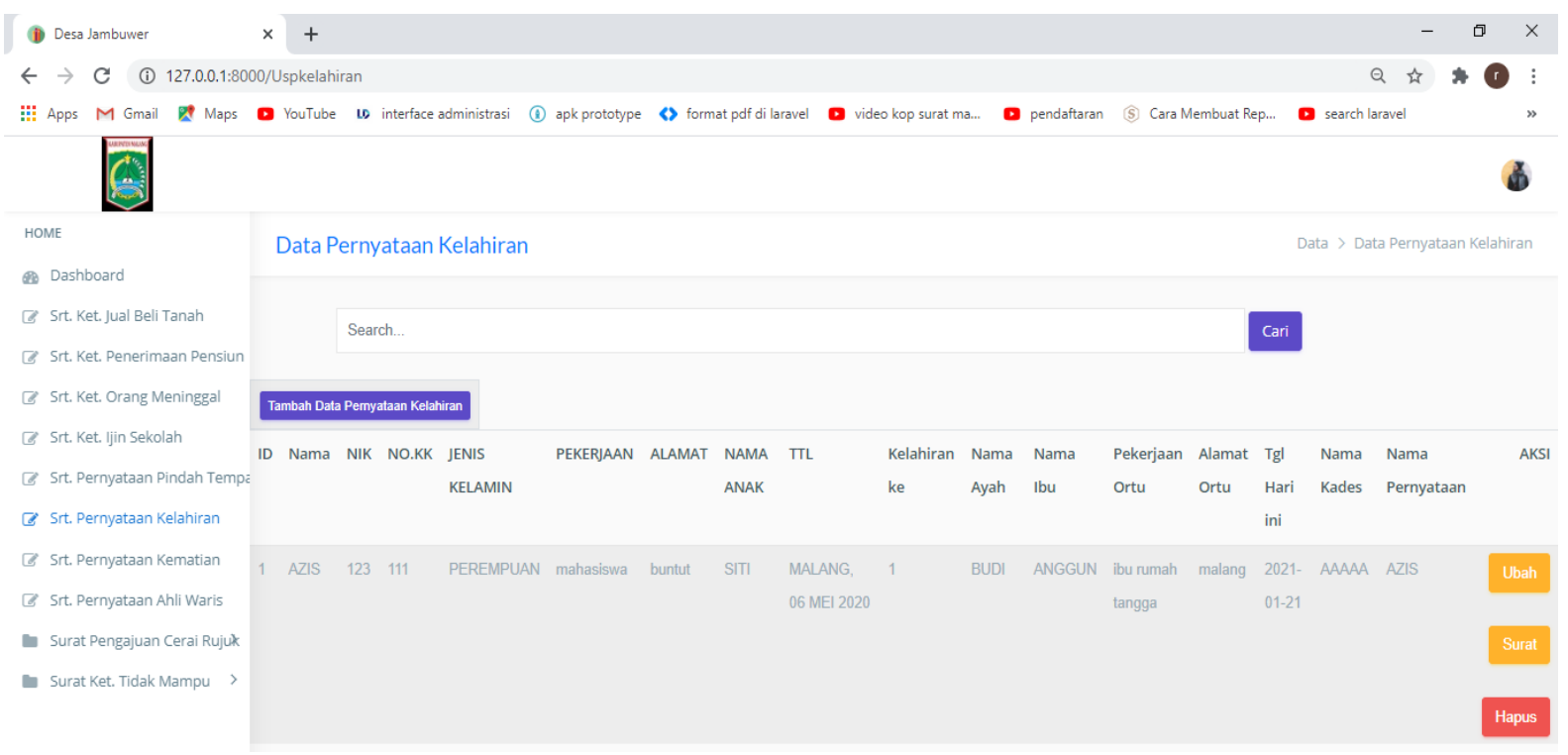

Gambar 16. Tampilan Halaman Kelola Surat Pernyataan Kelahiran

\section{KESIMPULAN}

Setelah melakukan penelitian berdasarkan pembahasan pada bab sebelumnya, maka dapat ditarik kesimpulan yaitu :

1. Sistem informasi administrasi desa jambuwer untuk Kelurahan Jambuwer berbasis web telah dikembangkan dengan menggunakan metode incremental sebagai metode pengembangan perangkat lunak.

2. Tahapan pengujian dilakukan menggunakan metode UAT untuk mengetahui penerimaan pengguna terhadap sistem informasi administrasi desa jambuwer. Dari hasil yang didapatkan pada pengujian UAT mendapatkan hasil yang baik dan dapat diterima oleh pengguna sistem tetapi dengan beberapa catatan pada fitur Admin tambah data RW yaitu kurangnya kolom nama ketua RW yang ditambahkan disetiap dusun, dan tambah data RT yaitu kurangnya kolom nama ketua RT yang ditambahkan disetiap dusun. 


\section{UCAPAN TERIMA KASIH}

Terima kasih disampaikan kepada seluruh pihak di Universitas Muhammadiyah Malang dan Seluruh Perangkat Desa Jambuwer pada khususnya atas dukungan dalam pemberian data dan informasi yang dibutuhkan oleh peneliti guna terselesaikannya penelitian ini.

\section{REFERENCES}

[1] M. R. Tsani, "Sistem Informasi Ujian Berbasis Web Server Smk Bina Islam Mandiri (Bisma) Kersana Brebes Tegal,” CogITo Smart Journal, vol. 1, no. 1, pp. 45-54, 2016.

[2] F. Noviyanto, T. Setiadi, and I. W. Ahmad, "Implementasi Sikades (Sistem Informasi Kependudukan Desa) Untuk Kemudahan Layanan Administrasi Desa Berbasis Web Mobile,” Jurnal Informatika Ahmad Dahlan, vol. 8, no. 1, 2014.

[3] A. Ibrahim and E. Lestari, "Pengembangan Model Sistem Informasi Integrated Laboratory pada Perguruan Tinggi," Proceeding KNTIA, vol. 1, no. 2, pp. 1-7, 2012

[4] R. S. Pressman, Software Engineering: A Practitioner's Approach. 2010

[5] S. Paryanta and D Susilowati, "Sistem Informasi Administrasi Kependudukan Berbasis Web Desa Sawahan,” IJSE-Indones. J. Softw. Eng, vol. 3, no. 2, pp. 77-81, 2017.

[6] A. Saputra, "Kajian Kebutuhan Perangkat Lunak Untuk Pengembangan Sistem Informasi dan Aplikasi Perangkat Lunak Buatan Lapan Bandung," Berita Dirgantara, vol. 13, no. 2, pp. 50-56, 2012.

[7] I. W. W. Karsana, "Rancang Bangun Sistem Informasi Nilai Akademik Berbasis Sms Gateway Pada Universitas Dhyana Pura," Sistemasi: Jurnal Sistem Informasi, vol. 8, no. 1, pp. 114-125, 2019.

[8] R. Wahyuniardi, L. H. Afrianti, S. Nurjaman, and W. Gusdya, "Sistem Informasi Berbasis Web untuk Monitoring dan Evaluasi Sentra Industri Kecil Alas Kaki di Jawa Barat,” Jurnal Ilmiah Teknik Industri, vol. 14, no. 2, pp. 174-186, 2016.

[9] E. C. Foster and S. Godbole, Overview of Microsoft SQL Server. Apress, 2016.

[10] S. Susanti, E. Junianto, and R. Rachman, "Implementasi Framework Laravel Pada Aplikasi Pengolah Nilai Akademik Berbasis Web,” Jurnal Informatika, vol. 4, no. 1, 2017. 